\title{
A genome-wide survey for prion-regulated miRNAs associated with cholesterol homeostasis
}

\author{
Judith Montag ${ }^{1}$, Markus Brameier², Ann-Christin Schmädicke', Sabine Gilch, ${ }^{3,4}$, Hermann M Schätzl ${ }^{3,4}$ \\ and Dirk Motzkus ${ }^{1 *}$
}

\begin{abstract}
Background: Prion diseases are neurodegenerative diseases that are characterized by the conversion of the cellular prion protein $\left(\mathrm{PrP}^{\mathrm{C}}\right.$ ) into a pathogenic isoform $\left(\mathrm{PrP}^{\mathrm{SC}}\right)$. It is known that neurodegeneration is often accompanied by the disturbance of cholesterol homeostasis. We have recently identified a set of genes that were upregulated after prion infection of N2a neuronal cells (Bach et al., 2009).

Results: We have now used ultra-deep sequencing technology to profile all microRNAs (miRNA) that could be associated with this effect in these N2a cells. Using stringent filters and normalization strategies we identified a small set of miRNAs that were up- or downregulated upon prion infection. Using bioinformatic tools we predicted whether the downregulated miRNAs could target mRNAs that have been previously identified to enhance cholesterol synthesis in these cells. Application of this joint profiling approach revealed that nine miRNAs potentially target cholesterol-related genes. Four of those miRNAs are localized in a miRNA-dense cluster on the mouse X-chromosome. Among these, twofold downregulation of mmu-miR-351 and mmu-miR-542-5p was confirmed by qRT-PCR. The same miRNAs were predicted as putative regulators of the sterol regulatory element-binding factor 2 (Srebf2), the low-density lipoprotein receptor (Ldlr) or the IPP isomerase.
\end{abstract}

Conclusions: The results demonstrate that joined profiling by ultra-deep sequencing is highly valuable to identify candidate miRNAs involved in prion-induced dysregulation of cholesterol homeostasis.

Keywords: Prion disease, Cholesterol, MicroRNA, Ultra-deep sequencing, Joint-profiling

\section{Background}

Transmissible spongiform encephalopathies (TSE) or prion diseases comprise a group of neurodegenerative diseases that include bovine spongiform encephalopathy (BSE) in cattle, scrapie in sheep, and Creutzfeldt-Jakob disease (CJD) in humans [1]. Prion diseases are associated with the conversion of the cellular prion protein $\left(\operatorname{PrP}^{\mathrm{C}}\right)$ into a pathogenic isoform $\left(\mathrm{PrP}^{\mathrm{SC}}\right)$ [2,3]. Aggregation of $\mathrm{PrP}^{\mathrm{Sc}}$ in neurons coincides with neuronal decay that finally leads to neurodegeneration. The molecular mechanism underlying prion-induced metabolic changes within infected cells are still poorly understood [4-6].

Several lines of evidence indicate that imbalances in the homeostasis of cholesterol are linked to the progression of neurodegenerative disorders including prion

\footnotetext{
* Correspondence: dmotzkus@dpz.eu

${ }^{1}$ German Primate Center, Unit of Infection Models, Kellnerweg, 4, 37077

Göttingen, Germany

Full list of author information is available at the end of the article
}

diseases [7-9]. Membrane-bound cholesterol is essential for the localization of $\operatorname{PrP}^{C}$ in lipid rafts and for the formation of $\operatorname{PrP}^{\mathrm{Sc}}$ [10]. Inhibition of cholesterol biosynthesis reduces the formation of $\operatorname{PrP}^{\mathrm{Sc}}$ and prolongs the survival time of scrapie-infected mice [11-13]. Cell culture models have been widely used to identify molecules that link cholesterol synthesis to $\operatorname{PrP}^{\mathrm{Sc}}$ formation [14]. Prion infected neuroblastoma cells upregulate a number of genes, among others HMG-CoA synthase (Hmgcs), HMG-CoA reductase (Hmgcr), IPP isomerase (Idi1), and the sterol regulatory element binding factor 2 (Srebf2), that are involved in the cholesterol biosynthesis pathway. In addition, expression of the low density lipoprotein (Ldl)-receptor is enhanced and leads to an increased uptake of cholesterol after prion infection [15].

Both, uptake and synthesis of cholesterol [16-20] as well as maintenance of hepatic function [21] are essentially influenced by the action of microRNAs (miRNAs). MiRNAs are potent regulators of gene expression that 
can act on the posttranscriptional level. These on average 22 nt long non-protein coding RNAs are derived from primary transcripts (pri-miRNA) that are sequentially processed into their mature form by the RNase III type nucleases DROSHA and DICER [22]. The mature miRNAs are sequestered into RNA-induced silencing complexes (RISCs) and recruit complementary mRNAs that, as a result, are degraded or translationally repressed [23]. Evidence accumulates that miRNAs are also involved in most neurodegenerative disorders that include Parkinsonism [24], Huntington's Chorea [25], Alzheimer's disease [26], and also prion disease [27,28].

Since miRNAs reduce the transcript levels of their target mRNAs on a genome-wide scale [29-33], the parallel examination of a miRNome and a transcriptome combined with a miRNA target analysis can be used to identify miRNA:mRNA interaction partners. This so-called "genome-wide joint profiling" has been successfully applied to identify pathologically relevant miRNA:mRNA interactions in Alzheimer's disease [34] and neuronal HIV-infection [35].

In the present study we applied joint profiling to prion-infected neuronal cell cultures. Using ultra-deep sequencing we obtained several millions of small RNA sequence reads. Stringent filtering, co-expression and target analysis identified nine miRNAs that showed multiple targets in cholesterol-dependent mRNAs. Four of those miRNAs, namely mmu-miR-351, mmu-miR-503, mmu-miR-503*, and mmu-miR-542-5p, are clustered in a miRNA dense region on the mouse X-chromosome. Our results show that joint profiling of miRNA and mRNA is an effective approach to identify relevant miRNA:mRNA candidate pairs that could be used for functional studies in prion-induced dysregulation of cholesterol homeostasis.

\section{Methods}

\section{RNA extraction}

The mouse neuroblastoma cell line N2a (CCL-131, American type Culture Collection, Rockville, MD) was cultured and sibling clones were infected in parallel with brain homogenate from scrapie-infected mice (strain $22 \mathrm{~L}$ ) or from healthy controls as previously described [15]. After the $18^{\text {th }}$ passage RNA was extracted with the RNeasy mini kit (Qiagen). The integrity of the RNA samples was determined by capillary electrophoresis on a Bioanalyzer (Agilent Technologies) according to the supplier's instructions. The RNA concentration was determined photometrically at $260 \mathrm{~nm}$ on a NanoDrop (PeqLab) and $5 \mu \mathrm{g}$ of each sample were applied to ultra-deep sequencing.

\section{Ultra-deep sequencing of small RNAs}

Construction of cDNA libraries, cluster generation and subsequent ultra-deep sequencing on a Solexa/Illumina platform was performed at the Allan Wilson Centre Genome Service (AWCGS), New Zealand. In brief, $5 \mu \mathrm{g}$ of total RNA from each sample was size-fractionated by $15 \%$ polyacrylamide electrophoresis (PAGE). The small RNA fraction (18-35 nucleotides (nt)) was extracted and ligated to 5'- and 3'-RNA adaptors using T4 RNA ligase. The RNA-adaptor constructs were purified and reverse transcribed. Clusters were generated by hybridization of the samples to the flow cell, chemical conversion to ssDNA, blocking of the 3'-OH and hybridization of sequencing primers. Ultra-deep sequencing was performed using one flow cell channel per sample.

\section{Bioinformatic analyses}

Compression of library data was achieved by annotating the frequency of each unique sequence into its respective identifier, thereby removing multiple reads in FASTA format. Sequences with a frequency $<10$ were discarded. Both preprocessing steps were implemented as Perl scripts and led to a speed-up of all further computations by a factor of about 18 . Processed libraries were aligned to miRBase release 14.0 with NCBI BLAST (blastall version 2.2.18) using standard settings without DUST filter (option -F F). Identification of miRNAs by BLAST required perfect alignment over the total miRNA length minus a tolerance offset of $3 \mathrm{nt}$. MiRNA target sites in the 3'-UTR of murine mRNAs Srebf2, Hgmcr, Hgmcs1, Mvk, Idi1, Fdft1, Cyp51, Sc4mol, and Ldlr were predicted using miRanda (version 3.0; [36]) with the following parameter settings: minimum score 130, minimum free energy $-19 \mathrm{kcal} / \mathrm{mol}$, conservation off, scaling parameter 4, gap open penalty -8.0 , gap extend penalty -4.0. Ribosomal 28S, $18 \mathrm{~S}, 5.8 \mathrm{~S}$ and $5 \mathrm{~S}$ rRNAs were BLASTed against miRBase release 14.0.

\section{miRNA profiling by quantitative real-time PCR}

Ten ng of total RNA from scrapie- and mock-infected N2a cells were reverse transcribed (TaqMan MicroRNA Reverse Transcription Kit, Applied Biosystems). The relative expression levels of mmu-miR-503, mmu-miR-503*, mmu-miR-351 and mmu-miR-542-5p was determined in a stem-loop based quantitative real-time PCR (qRT-PCR) assay (TaqMan MicroRNA Assay, Applied Biosystems) according to the supplier's instructions. Cycling was performed after initial denaturation for $10 \mathrm{~min}$ at $95^{\circ} \mathrm{C}$ for 45 cycles with $95^{\circ} \mathrm{C}$ for $15 \mathrm{sec}$ and $60^{\circ} \mathrm{C}$ for $45 \mathrm{sec}$ in a 7500 Real Time PCR System (Applied Biosystems). Relative expression levels were calculated according to the $\Delta \Delta C$ T-method [37] using the non-regulated miRNA hsa-miR-106b* as a housekeeping RNA. Statistical significance was determined by two way ANOVA with Bonferroni post test (**** $\mathrm{p}<0.001)$. 


\section{Results}

In the present study we applied joint profiling to prioninfected neuronal cell cultures. Therefore we performed co-expression analysis of miRNAs and mRNAs combined with a stringent miRNA target prediction to identify relevant miRNA:mRNA pairs. This combined approach will be referred to as joint profiling. Reliable joint profiling by a direct comparison of miRNA and mRNA expression data depends on the use of identical samples for both studies. Thus we have used the prioninfected neuroblastoma N2a cell model that had been generated for whole genome transcriptome profiling [15]. In brief, the N2a cells were infected in parallel with brain homogenate derived from terminally ill mice infected with the scrapie strain $22 \mathrm{~L}(\mathrm{ScN} 2 \mathrm{a})$ or from mock-infected healthy mice (N2a-mock) as previously reported [15]. We then extracted total RNA from ScN2a and N2a-mock cells. To confirm high quality RNA we conducted nano-scale electrophoresis that showed a high RNA integrity number (RIN) of 9.4 and 9.6 in both samples, respectively.

The recent development of high-throughput sequencing technologies (also referred to as ultra-deep sequencing) allows for the comprehensive recording of all nucleic acid sequences in virtually any biological sample. We decided to use the Solexa platform that is especially suitable for miRNA analysis due to its immense capacity to generate high numbers of short sequence reads with high accuracy. To achieve the highest possible sensitivity both samples were enriched for small RNAs with a cut-off range from 18 to $35 \mathrm{nt}$. To further increase the sequencing depth (i.e. number of sequence reads per sample) we used one capillary per sample with a capacity of approximately 175 million base pairs. Our ultra-deep sequencing analysis resulted in the generation of $5.8 \times 10^{6}$ and $4.2 \times 10^{6}$ sequence reads from ScN2a and N2a-mock cells, respectively.

For the generation of miRNA profiles from these libraries, successive filtering and normalization steps were implemented (Figure 1). As a first step, compression of data was achieved by merging of identical sequence reads and encoding their frequency into the respective sequence identifier. Since the population of small RNAs must be expected to include mRNA degradation products with limited significance [38] we increased the specificity of our dataset by exclusion of rare sequences. We arbitrarily applied a cut-off for reads with a frequency $<10$. It should be noted that this stringent cutoff results in loss of information, but is required to reduce the expected false positive rate. Identification of all expressed murine miRNAs in our samples was achieved by annotation of the filtered dataset to the miRBase 14.0. Our BLAST analysis allowed up to three mismatches at the 5'- or 3'-end of each miRNA,

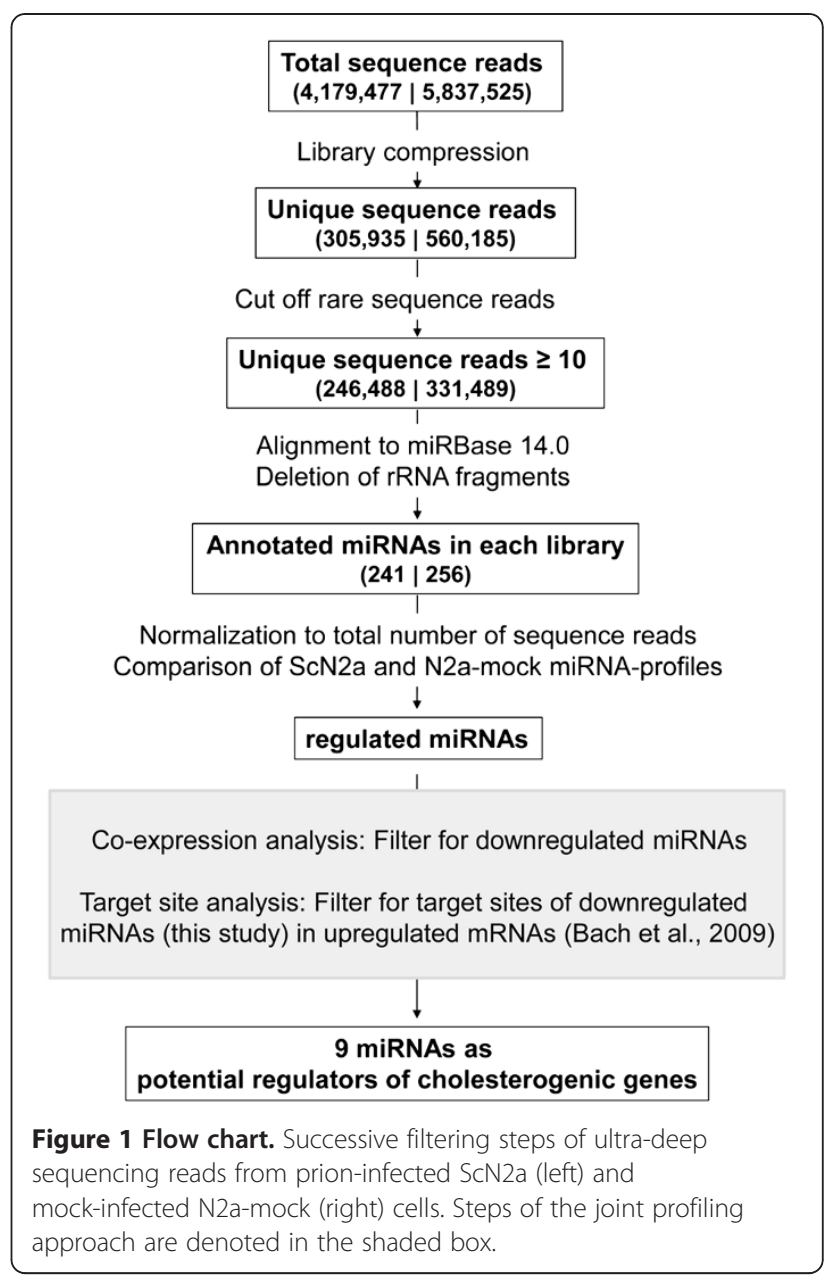

respectively. Although this leads to loss of specificity regarding closely related miRNAs, it enabled the identification of miRNA-processing variants that differ from the miRBase entries $[39,40]$.

To date, several miRNAs have been removed from miRBase due to the fact that the sequences were identical to ribosomal RNAs (rRNAs), e.g. miR-560 and hsamiR-923 from miRBase release 13.0 (ftp://mirbase.org/ pub/mirbase/13.0/miRNA.dead.gz). To ensure that our dataset would not include such rRNA-derived sequences, we did an additional BLAST analysis that compared the entire murine miRBase dataset with mouse $28 \mathrm{~S}, 18 \mathrm{~S}, 5 \mathrm{~S}$ and $4.5 \mathrm{~S}$ rRNA NCBI entries. We found that 16 miRNAs appeared to be rRNA fragments and thus were removed from our analysis. Most, but not all of these rRNA fragments were also described by others [41] and have meanwhile been deleted from mirBase. However, mmumiR-709 and mmu-miR-1195 are identical to ribosomal sequences and still valid in the current mirBase release 19.

After this successive filtering we identified $256 \mathrm{miR}$ NAs expressed in mock-infected and 241 expressed in 
scrapie-infected N2a cells, which collectively correspond to 261 individual miRNAs (Additional file 1).

For the identification of regulated miRNAs, the libraries derived from scrapie-infected and mock-infected cells needed to be normalized. The normalization of ultra deep sequencing data has been reported to be a crucial step in interpreting regulation [38]. Parameswaran and colleagues have described two alternative methods, (1) the normalization to total small RNAs sequenced for each library or (2) the normalization against the total number of miRNAs in the respective samples. Applying both normalization methods to our filtered datasets we obtained similar results (data not shown). However, normalization against the total number of miRNAs bears the risk of creating a bias in case that a high proportion of miRNAs is regulated. Therefore we chose to normalize against the total number of sequence reads.

Next we aimed to identify miRNAs that were differentially expressed in scrapie-infected cells as compared to mock-infected controls. Regulation of miRNAs was considered to be robust if the relative abundance differed at least twofold between both libraries. Using this analysis strategy we found 14 upregulated and seven downregulated miRNAs in addition to a number of miRNAs that were solely expressed in ScN2a or N2a-mock cells. Since we had restricted our analysis to sequences that had been read more than ten times, we filtered the solely expressed miRNAs for those that were detected more than 20 times to reach the criterion of twofold regulation. Six miRNAs from N2a-mock cells matched this criterion and were termed "downregulated" without assigning a specific regulation factor. The resulting 14 upregulated and 13 downregulated miRNAs with their corresponding sequence reads are listed in Table 1.

It is known that the upregulation of miRNAs results in the downregulation of their specific target genes. Vice versa, downregulation of miRNAs could lead to the upregulation mRNA levels, presumably by a derepression mechanism [42]. Accordingly, some or all of the 13 downregulated miRNAs may be responsible for the upregulation of those mRNAs that induce prionassociated disturbance of cholesterol homeostasis.

In the light of these considerations we conducted a miRNA target search. We examined the 3'-UTRs of the cholesterogenic mouse genes (Srebf2, Hgmcs, Hgmcr, Mvk, Idi1, Fdft1, CYP51, Sc4mol, and Ldlr; [15]) for putative binding sites for the 13 downregulated miRNAs. Four out of 13 miRNAs were not predicted to bind any of the nine target genes. However, nine miRNAs showed multiple targets in at least one of these mRNAs (Table 2). Interestingly, four of those miRNAs, namely mmu-miR351, mmu-miR-503, mmu-miR-503*, and mmu-miR$542-5 \mathrm{p}$ are located in a genomic cluster within $5 \mathrm{~kb}$ on the mouse X-chromosome.
Table 1 Regulated miRNAs in ScN2a cells as compared to mock infected controls

\begin{tabular}{|c|c|c|c|}
\hline \multirow[t]{2}{*}{ miRNA } & \multicolumn{2}{|c|}{ Number of reads } & \multirow{2}{*}{$\begin{array}{l}\text { Regulation factor } \\
\text { (normalized to total } \\
\text { reads per library) }\end{array}$} \\
\hline & N2a-mock & ScN2a & \\
\hline mmu-miR-351 & 88 & 0 & downregulated \\
\hline mmu-miR-139-5p & 21 & 0 & downregulated \\
\hline mmu-miR-690 & 35 & 0 & downregulated \\
\hline mmu-miR-330* & 36 & 0 & downregulated \\
\hline mmu-miR-378* & 22 & 0 & downregulated \\
\hline mmu-miR-485* & 27 & 0 & downregulated \\
\hline mmu-miR-375 & 65 & 11 & -4.23 \\
\hline mmu-miR-503 & 64 & 12 & -3.82 \\
\hline mmu-miR-203 & 47 & 10 & -3.37 \\
\hline mmu-miR-542-5p & 46 & 14 & -2.35 \\
\hline mmu-miR-322* & 33 & 11 & -2.15 \\
\hline mmu-miR-503* & 29 & 10 & -2.08 \\
\hline mmu-miR-125b-3p & 43 & 15 & -2.05 \\
\hline mmu-miR-15b* & 36 & 52 & 2.02 \\
\hline mmu-miR-598 & 83 & 120 & 2.02 \\
\hline mmu-miR-411 & 41 & 60 & 2.04 \\
\hline mmu-miR-743b-5p & 47 & 69 & 2.05 \\
\hline mmu-miR-126-3p & 70 & 106 & 2.12 \\
\hline mmu-miR-708 & 22 & 34 & 2.16 \\
\hline mmu-miR-883a-3p & 10 & 16 & 2.23 \\
\hline mmu-miR-181d & 184 & 295 & 2.24 \\
\hline mmu-miR-210 & 223 & 370 & 2.32 \\
\hline mmu-miR-497 & 13 & 22 & 2.36 \\
\hline mmu-miR-101a & 12 & 21 & 2.44 \\
\hline mmu-miR-181c & 33 & 61 & 2.58 \\
\hline mmu-miR-128 & 30 & 58 & 2.70 \\
\hline mmu-miR-338-5p & 10 & 23 & 3.21 \\
\hline
\end{tabular}

We next validated the regulation of the miRNAs from this cluster (mmu-miR-351, mmu-miR-503, mmu-miR503*, and mmu-miR-542-5p) by qRT-PCR. For normalization we used the mmu-miR-106b* as a housekeeping miRNA, presuming that it was expressed at constant and robustly high levels. Using a commercial kit, mmu-miR-503 was not detected by qRT-PCR analysis. To provide comparability among the quantification of the different miRNAs we did not modify the recommended protocol of the commercial detection kit in order to achieve detection of mmu-miR-503. In comparison, mmu-miR-503* could be detected, however, we could not confirm regulation. The fact that in ultra-deep sequencing the number of sequence reads and the upregulation factors were both at the borderline may have 
Table 2 Predicted target sites in the 3'-UTR of genes involved in the cholesterogenic pathway for downregulated miRNAs

\begin{tabular}{|c|c|c|c|c|c|c|c|c|c|}
\hline \multirow[t]{2}{*}{ miRNA } & \multirow[t]{2}{*}{ Coordinates (NCBIM37) } & \multicolumn{8}{|c|}{ Number of targets } \\
\hline & & Hgmcs 1 & Hgmcr & Idi1 & Fdft1 & CYP51 & Sc4mol & Ldlr & Srebf2 \\
\hline mmu-miR-139-5p & 7: 108623890-108623957[+] & & & & & 1 & & & \\
\hline mmu-miR-330* & 7: 19766814-19766911 [+] & 1 & 2 & & 1 & & & 2 & \\
\hline mmu-miR-125b-3p & 9: 41390009-41390085 [+] & & & 1 & 1 & 1 & & 1 & \\
\hline mmu-miR-690 & 16: $28600021-28600129[-]$ & & & & & 1 & & & \\
\hline mmu-miR-378* & 18: 61557489-61557554 [-] & & & & & 2 & & & \\
\hline mmu-miR-503 & $X: 50407161-50407231[-]$ & & & 1 & 2 & & & 2 & \\
\hline mmu-miR-503* & $X: 50407161-50407231[-]$ & & 1 & & & & & & \\
\hline mmu-miR-351 & $X: 50406432-50406530[-]$ & 1 & 1 & 1 & & 1 & & 5 & 3 \\
\hline mmu-miR-542-5p & $X: 50402580-50402664[-]$ & & & 1 & & & & & \\
\hline
\end{tabular}

prevented the robust detection of miR-503*-regulation by qRT-PCR. However, the regulation of the more abundantly expressed miRNAs mmu-miR-351 and -542-5p was confirmed by qRT-PCR, indicating to a high validity of the ultra-deep sequencing (Figure 2). Furthermore the magnitude of downregulation in scrapie-infected versus mock-infected cells of mmu-miR-351 and mmu-miR542-5p was comparable to that estimated by ultra-deep sequencing. In summary, our joint profiling approach lead to the identification of two miRNA candidates that correlate with disturbance in cholesterol homeostasis in prion-infected cells.

\section{Discussion}

Ultra-deep sequencing represents a powerful technology for the comprehensive assessment of the whole miRNome in a given sample in a presumably unbiased manner. Using Solexa technology we have generated five million independent short sequence reads per sample. Highly abundant miRNAs, such as mmu-let-7c, mmumiR-24, and mmu-miR-99b were sequenced on average 20,000 times. This corresponds to an enhanced sensitivity of three orders of magnitude in comparison to traditional cloning and subsequent Sanger sequencing strategies in early pioneer studies [43]. Since high sensitivity mostly results in reduced specificity we used a panel of stringent filters to identify miRNAs that were robustly expressed. Contemporaneously we could exclude fragments derived from ribosomal RNA that were misleadingly annotated as miRNAs in miRBase 14.0. The high specificity of our approach is reflected by the detection of more than 1,000 sequence reads of the neuronally expressed paralogues miR-103/107 [44] and miR30a/d [45], whereas liver-enriched miR-122 was not expressed in N2a cells. This is in accordance with previous studies that did not detect significant amounts of these miRNAs in the brain $[28,43,46]$.
Ultra-deep sequencing data can be used for relative quantification, but the resulting accuracy is strictly dependent on the used scaling method [47]. We have normalized our miRNAs expression profiles to the respective library size as suggested [48]. To ensure the applicability of this normalization method to identify regulated miRNAs we performed qRT-PCR. By comparison of these two independent methods we could confirm downregulation of mmu-miRs -351 and $-542-5 p$. Furthermore, the observed differences in miRNA expression were consistent, regardless whether they were determined by UDS or qRT-PCR, although significant regulation of one miRNA could not be confirmed.

It was recently reported that murine mmu-miRNA-146a is upregulated in scrapie [27], and BSE-infected [49] mice. miR-146a can be activated upon LPS treatment via Tolllike receptors TLR2 and TLR4. Upon overexpression, mmu-miR-146a modulates transcription of genes involved in cell movement and adhesion, mediators of inflammation and a set of genes involved in RNA posttranscriptional regulation [49]. Comparison of N2a vs ScN2a cells revealed a 1.6 fold upregulation of mmumiR-146a that failed to match our criteria for further analysis. This is similar to the regulation upon BSE-infection in macaques [28]. It may also reflect the specificity of certain microRNAs in rare human prion diseases that was recently reported [50].

Our approach revealed 14 upregulated and 13 downregulated miRNAs in $\mathrm{ScN} 2 \mathrm{a}$ cells as compared to mock-infected controls. The downregulated miRNAs were used as queries for target analysis to identify mutual miRNA:mRNA interaction partners that might be responsible for prion-associated induction of cholesterol synthesis. Linking a miRNA to its downstream targets is a major challenge in miRNA biology and only few miRNA:mRNA pairs have been experimentally confirmed yet. A variety of bioinformatic algorithms have been developed which predict potential binding sites 


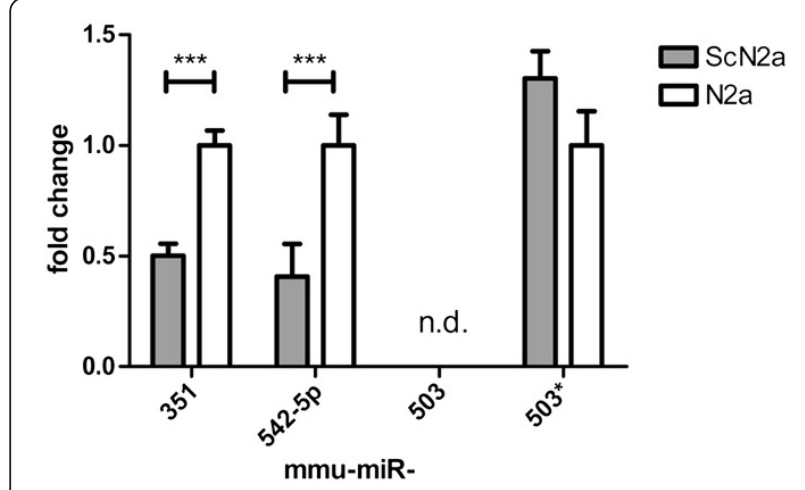

Figure 2 qRT-PCR analysis of clustered miRNAs in scrapie-infected N2a cells. Ten ng of total RNA from ScN2a and N2a-mock cells were applied to miRNA-specific cDNA synthesis. Subsequent qRT-PCR was performed using equivalent amounts of 1.3 ng RNA. Relative miRNA expression was analyzed by $\Delta \Delta C_{T}$ method [37] using the non-regulated miRNA mmu-miR-106b* as a housekeeping RNA and the non-infected cells as a calibrator. Statistical significance was determined by student-t-test (nonparametric with Welch's correction, $\left.{ }^{* * *} p<0.001\right)$. The mean regulation factor \pm SD of duplicates from three independent experiments are shown. Abbreviation n.d.; not detected.

within the 3'-untranslated regions (UTRs) of mRNAs [51]. Some, but not all limitations of miRNA target predictions are caused by the inaccuracy of the underlying algorithm. Identification of relevant miRNA:mRNA pairs can also fail if one, the miRNA or the mRNA, is not present in the relevant cell or tissue. Using our miRNA expression profile and the known mRNA expression profile of the N2a cells we could strongly limit the assumed production of false positive or false negative results. We used the miRanda algorithm [36] to predict putative binding sites of the downregulated miRNAs in the 3'-UTRs of prion-induced mRNAs related to cholesterol homeostasis [15].

Four downregulated miRNAs could not be linked to the upregulated cholesterogenic genes. These miRNAs have neither been described to be involved in cholesterol homeostasis nor in prion disease. However, nine out of the 13 downregulated miRNAs were predicted to have at least one target site in the 3'-UTR of the examined mRNAs. Notably four of these miRNAs reside within a $6 \mathrm{~kb}$ cluster on the mouse X-chromosome. To our knowledge, this is the first time that this cluster is correlated to neurogenic cholesterol metabolism. A putative function of the homologous microRNA cluster in humans has been recently described. The concerted regulation of cluster-derived miRNAs promoted cell cycle arrest and differentiation in myocytes [52] and in monocytes [53]. Co-expression of clustered miRNAs that results in cooperative function has been discovered in several biological systems such as development [54], stem cell differentiation [55], or viral infection [56].
Interestingly we also identified two upregulated miRNAs, mmu-miR-883a-3p and mmu-miR-743b-5p, that were localized on a second X-chromosomal cluster. Additional five miRNAs that reside in this cluster did not match our stringent criteria, but were upregulated more than 1.5 fold. Whether regulation of these clusters is a cause or a consequence of prion infection remains unknown. $\mathrm{N} 2 \mathrm{a}$ is a polyploid cell line with a mean number of chromosomes around 100 and an unstable chromosomal content upon passaging and even within the same culture [57]. Whether or not the expression of the Xchromosomal miRNA cluster is also influenced by the used cell culture conditions cannot be estimated.

It should be noted that the expression of miRNAs are highly cell- and tissue-specific. Thus differences in miRNA expression between prion-infected and noninfected N2a cells may not reflect miRNA dysregulation in brains of prion-diseased mice or humans. Consequently, the question whether our findings may also have an indication for human prion diseases cannot be answered by our study. However, since imbalances in neuronal cholesterol homeostasis plays a pivotal role in several human neurodegenerative diseases, including Alzheimer's disease [58], Huntington's chorea [59,60], and Niemann Pick disease type C [61] our results may be useful to elucidate the mechanism that underlies cholesterol dysregulation. Future studies that will focus on the identification of putative targets of miR-351 and miR-542-5p need to be carried out to reinforce the significance of our results.

\section{Conclusion}

We have identified a number of regulated miRNAs in a cell culture model for prion diseases by the use of ultradeep sequencing. Using a joint profiling approach we found that the X-chromosomal clustered mmu-miRs-351 and 542-5p could target genes that are involved in prioninduced dysregulation of cholesterol homeostasis. Our results show that semi-quantitative analysis of ultra-deep sequencing data is capable to identify differentially regulated miRNAs from biological samples.

\section{Additional file}

Additional file 1: miRNA expression profiles of ScN2a and

N2a-mock cells.

Competing interests

The authors declare that they have no competing interests.

Authors' contributions

DM designed research, MB performed bioinformatics, HSM and SG produced and provided samples, ACS performed qRT-PCR, DM and JM wrote the manuscript with contributions from all authors. All authors read and approved the final manuscript. 


\section{Acknowledgements and funding}

The authors would like to thank Christian Bach for sample preparation. Current address of JM is Molecular and Cell Physiology, Hannover Medical School, Carl-Neuberg-Str. 1, D-30625 Hannover. This work was supported by the Alberta Prion Research Institute (APRI, 20080238), the Ministry for Science and Culture of Lower Saxony, SFB-596, and the EU Network of Excellence Neuroprion. The funders had no role in study design, data collection and analysis, decision to publish, or preparation of the manuscript.

\section{Author details}

'German Primate Center, Unit of Infection Models, Kellnerweg, 4, 37077 Göttingen, Germany. ${ }^{2}$ German Primate Center, Primate Genetics Laboratory, Kellnerweg 4, 37077 Göttingen, Germany. Institute of Virology, Technical University of Munich (TUM), Trogerstrasse 30, D-81675 Munich, Germany. ${ }^{4}$ Wyoming Excellence Chair in Prion Biology, Department of Veterinary Sciences and of Molecular Biology, University of Wyoming, 1000 E. University Ave, Laramie, USA.

Received: 8 November 2011 Accepted: 10 September 2012 Published: 17 September 2012

\section{References}

1. Chesebro B: Introduction to the transmissible spongiform encephalopathies or prion diseases. Br Med Bull 2003, 66:1-20

2. Prusiner SB: Molecular biology of prion diseases. Science (New York, NY) 1991, 252(5012):1515-1522.

3. Pan KM, Baldwin M, Nguyen J, Gasset M, Serban A, Groth D, Mehlhorn I, Huang Z, Fletterick RJ, Cohen FE, et al: Conversion of alpha-helices into beta-sheets features in the formation of the scrapie prion proteins. Proc Natl Acad Sci U S A 1993, 90(23):10962-10966.

4. Schatzl HM, Laszlo L, Holtzman DM, Tatzelt J, DeArmond SJ, Weiner RI, Mobley WC, Prusiner SB: A hypothalamic neuronal cell line persistently infected with scrapie prions exhibits apoptosis. J Virol 1997 71(11):8821-8831.

5. Gorodinsky A, Harris DA: Glycolipid-anchored proteins in neuroblastoma cells form detergent-resistant complexes without caveolin. J Cell Biol 1995, 129(3):619-627.

6. Christensen HM, Harris DA: Prion protein lacks robust cytoprotective activity in cultured cells. Mol Neurodegener 2008, 3:11.

7. Puglielli L, Tanzi RE, Kovacs DM: Alzheimer's disease: the cholesterol connection. Nat Neurosci 2003, 6(4):345-351.

8. De Strooper B, Saftig P, Craessaerts K, Vanderstichele H, Guhde G, Annaert W. Von Figura K, Van Leuven F: Deficiency of presenilin-1 inhibits the normal cleavage of amyloid precursor protein. Nature 1998, 391(6665):387-390

9. Tamboli IY, Prager K, Thal DR, Thelen KM, Dewachter I, Pietrzik CU, St George-Hyslop P, Sisodia SS, De Strooper B, Heneka MT, et al: Loss of gamma-secretase function impairs endocytosis of lipoprotein particles and membrane cholesterol homeostasis. J Neurosci 2008, 28(46):12097-12106.

10. Taraboulos A, Scott M, Semenov A, Avrahami D, Laszlo L, Prusiner SB: Cholesterol depletion and modification of $\mathrm{COOH}$-terminal targeting sequence of the prion protein inhibit formation of the scrapie isoform. J Cell Biol 1995, 129(1):121-132

11. Haviv Y, Avrahami D, Ovadia H, Ben-Hur T, Gabizon R, Sharon R: Induced neuroprotection independently from PrPSC accumulation in a mouse model for prion disease treated with simvastatin. Arch Neurol 2008, 65(6):762-775

12. Vetrugno V, Di Bari MA, Nonno R, Puopolo M, D'Agostino C, Pirisinu L, Pocchiari M, Agrimi U: Oral pravastatin prolongs survival time of scrapieinfected mice. J Gen Virol 2009, 90(Pt 7):1775-1780.

13. Mok SW, Thelen KM, Riemer C, Bamme T, Gultner S, Lutjohann D, Baier M: Simvastatin prolongs survival times in prion infections of the central nervous system. Biochem Biophys Res Commun 2006, 348(2):697-702.

14. Gilch S, Bach C, Lutzny G, Vorberg I, Schatzl HM: Inhibition of cholesterol recycling impairs cellular PrP(Sc) propagation. Cell Mol Life Sci 2009, 66(24):3979-3991.

15. Bach C, Gilch S, Rost R, Greenwood AD, Horsch M, Haij GN, Brodesser S, Facius A, Schadler $S$, Sandhoff $K$, et al: Prion-induced activation of cholesterogenic gene expression by Srebp2 in neuronal cells. J Biol Chem 2009, 284(45):31260-31269.
16. Esau C, Davis S, Murray SF, Yu XX, Pandey SK, Pear M, Watts L, Booten SL, Graham M, McKay R, et al: miR-122 regulation of lipid metabolism revealed by in vivo antisense targeting. Cell Metab 2006, 3(2):87-98.

17. Niopoulos D, Drosatos K, Hiyama Y, Goldberg IJ, Zannis VI: MicroRNA-370 controls the expression of microRNA-122 and Cpt1alpha and affects lipid metabolism. J Lipid Res 2010, 51(6):1513-1523.

18. Marquart TJ, Allen RM, Ory DS, Baldan A: miR-33 links SREBP-2 induction to repression of sterol transporters. Proc Natl Acad Sci U S A 2010, 107(27):12228-12232.

19. Najafi-Shoushtari SH, Kristo F, Li Y, Shioda T, Cohen DE, Gerszten RE, Naar AM: MicroRNA-33 and the SREBP host genes cooperate to control cholesterol homeostasis. Science (New York, NY) 2010, 328(5985):1566-1569.

20. Rayner KJ, Suarez Y, Davalos A, Parathath S, Fitzgerald ML, Tamehiro N, Fisher EA, Moore KJ, Fernandez-Hernando C: MiR-33 contributes to the regulation of cholesterol homeostasis. Science (New York, NY) 2010, 328(5985):1570-1573.

21. Gatfield D, Le Martelot G, Vejnar CE, Gerlach D, Schaad O, Fleury-Olela F, Ruskeepaa AL, Oresic M, Esau CC, Zdobnov EM, et al: Integration of microRNA miR-122 in hepatic circadian gene expression. Genes Dev 2009, 23(11):1313-1326.

22. Bushati N, Cohen SM: microRNA functions. Annu Rev Cell Dev Biol 2007, 23:175-205.

23. Winter J, Jung S, Keller S, Gregory Rl, Diederichs S: Many roads to maturity: microRNA biogenesis pathways and their regulation. Nat Cell Biol 2009, 11 (3):228-234.

24. Kim J, Inoue K, Ishii J, Vanti WB, Voronov SV, Murchison E, Hannon G, Abeliovich A: A MicroRNA feedback circuit in midbrain dopamine neurons. Science (New York, NY) 2007 317(5842):1220-1224

25. Packer AN, Xing Y, Harper SQ, Jones L, Davidson BL: The bifunctional microRNA miR-9/miR-9* regulates REST and CoREST and is downregulated in Huntington's disease. J Neurosci 2008 28(53):14341-14346.

26. Lukiw WJ: Micro-RNA speciation in fetal, adult and Alzheimer's disease hippocampus. Neuroreport 2007, 18(3):297-300.

27. Saba R, Goodman CD, Huzarewich RL, Robertson C, Booth SA: A miRNA signature of prion induced neurodegeneration. PLOS One 2008, 3(11):e3652.

28. Montag J, Hitt R, Opitz L, Schulz-Schaeffer WJ, Hunsmann G, Motzkus D: Upregulation of miRNA hsa-miR-342-3p in experimental and idiopathic prion disease. Mol Neurodegener 2009, 4:36.

29. Lim LP, Lau NC, Garrett-Engele P, Grimson A, Schelter JM, Castle J, Bartel DP, Linsley PS, Johnson JM: Microarray analysis shows that some microRNAs downregulate large numbers of target mRNAs. Nature 2005, 433(7027):769-773

30. Baek D, Villen J, Shin C, Camargo FD, Gygi SP, Bartel DP: The impact of microRNAs on protein output. Nature 2008, 455(7209):64-71.

31. Bagga S, Bracht J, Hunter S, Massirer K, Holtz J, Eachus R, Pasquinelli AE: Regulation by let-7 and lin-4 miRNAs results in target mRNA degradation. Cell 2005, 122(4):553-563.

32. Cheng $C$, Li LM: Inferring microRNA activities by combining gene expression with microRNA target prediction. PLoS One 2008, 3(4):e1989.

33. Guo H, Ingolia NT, Weissman JS, Bartel DP: Mammalian microRNAs predominantly act to decrease target mRNA levels. Nature 2010, 466(7308):835-840

34. Nunez-Iglesias J, Liu CC, Morgan TE, Finch CE, Zhou XJ: Joint genome-wide profiling of miRNA and mRNA expression in Alzheimer's disease cortex reveals altered miRNA regulation. PLoS One 2010, 5(2):e8898.

35. Tatro ET, Scott ER, Nguyen TB, Salaria S, Banerjee S, Moore DJ, Masliah E, Achim CL, Everall IP: Evidence for Alteration of Gene Regulatory Networks through MicroRNAs of the HIV-infected brain: novel analysis of retrospective cases. PLoS One 2010, 5(4):e10337.

36. Enright AJ, John B, Gaul U, Tuschl T, Sander C, Marks DS: MicroRNA targets in Drosophila. Genome Biol 2003, 5(1):R1.

37. Winer J, Jung CK, Shackel I, Williams PM: Development and validation of real-time quantitative reverse transcriptase-polymerase chain reaction for monitoring gene expression in cardiac myocytes in vitro. Anal Biochem 1999, 270(1):41-49

38. Parameswaran P, Sklan E, Wilkins C, Burgon T, Samuel MA, Lu R, Ansel KM, Heissmeyer V, Einav S, Jackson W, et al: Six RNA viruses and forty-one 
hosts: viral small RNAs and modulation of small RNA repertoires in vertebrate and invertebrate systems. PLoS Pathog 2010, 6(2):e1000764.

39. Burroughs AM, Ando Y, de Hoon MJ, Tomaru Y, Nishibu T, Ukekawa R, Funakoshi T, Kurokawa T, Suzuki $H$, Hayashizaki $Y$, et al: A comprehensive survey of 3' animal miRNA modification events and a possible role for 3' adenylation in modulating miRNA targeting effectiveness. Genome Res 2010, 20(10):1398-1410.

40. Wu H, Ye C, Ramirez D, Manjunath N: Alternative processing of primary microRNA transcripts by Drosha generates 5 ' end variation of mature microRNA. PLoS One 2009, 4(10):e7566.

41. Chiang HR, Schoenfeld LW, Ruby JG, Auyeung VC, Spies N, Baek D, Johnston WK, Russ C, Luo S, Babiarz JE, et al: Mammalian microRNAs: experimental evaluation of novel and previously annotated genes. Genes Dev 2011, 24 (10):992-1009.

42. Zhao S, Liu MF: Mechanisms of microRNA-mediated gene regulation. Science in China 2009, 52(12):1111-1116.

43. Landgraf $P$, Rusu M, Sheridan R, Sewer A, lovino N, Aravin A, Pfeffer S, Rice A, Kamphorst AO, Landthaler M, et al: A mammalian microRNA expression atlas based on small RNA library sequencing. Cell 2007, 129(7):1401-1414.

44. Babak T, Zhang W, Morris Q, Blencowe BJ, Hughes TR: Probing microRNAs with microarrays: tissue specificity and functional inference. RNA 2004, 10(11):1813-1819.

45. Mellios N, Huang HS, Grigorenko A, Rogaev E, Akbarian S: A set of differentially expressed miRNAs, including miR-30a-5p, act as posttranscriptional inhibitors of BDNF in prefrontal cortex. Hum Mol Genet 2008, 17(19):3030-3042.

46. Lee EJ, Baek M, Gusev Y, Brackett DJ, Nuovo GJ, Schmittgen TD: Systematic evaluation of microRNA processing patterns in tissues, cell lines, and tumors. RNA (New York, NY) 2008, 14(1):35-42.

47. Linsen SE, de Wit E, Janssens G, Heater S, Chapman L, Parkin RK, Fritz B, Wyman SK, de Bruijn E, Voest EE, et al: Limitations and possibilities of small RNA digital gene expression profiling. Nat Methods 2009, 6(7):474-476.

48. Meyer SU, Pfaffl MW, Ulbrich SE: Normalization strategies for microRNA profiling experiments: a 'normal' way to a hidden layer of complexity? Biotechnol Lett 2010, 32(12):1777-1788.

49. Saba R, Gushue S, Huzarewich RL, Manguiat K, Medina S, Robertson C, Booth SA: MicroRNA 146a (miR-146a) is over-expressed during prion disease and modulates the innate immune response and the microglial activation state. PLoS One 2012, 7(2):e30832

50. Lukiw WJ, Dua P, Pogue Al, Eicken C, Hill JM: Upregulation of micro RNA146a (miRNA-146a), a marker for inflammatory neurodegeneration, in sporadic Creutzfeldt-Jakob disease (sCJD) and Gerstmann-StrausslerScheinker (GSS) syndrome. J Toxicol Environ Heal 2011, 74(22-24):1460-1468.

51. Majer A, Booth SA: Computational methodologies for studying noncoding RNAs relevant to central nervous system function and dysfunction. Brain Res 2010, 1338:131-145.

52. Sarkar S, Dey BK, Dutta A: MiR-322/424 and -503 are induced during muscle differentiation and promote cell cycle quiescence and differentiation by down-regulation of Cdc25A. Mol Biol Cell 2010, 21(13):2138-2149.

53. Forrest AR, Kanamori-Katayama M, Tomaru Y, Lassmann T, Ninomiya N, Takahashi Y, de Hoon MJ, Kubosaki A, Kaiho A, Suzuki M, et al: Induction of microRNAs, mir-155, mir-222, mir-424 and mir-503, promotes monocytic differentiation through combinatorial regulation. Leukemia 2010 24(2):460-466.

54. Mendell JT: miRiad roles for the miR-17-92 cluster in development and disease. Cell 2008, 133(2):217-222

55. Barroso-delJesus A, Romero-Lopez C, Lucena-Aguilar G, Melen GJ, Sanchez L, Ligero G, Berzal-Herranz A, Menendez P: Embryonic stem cell-specific miR302-367 cluster: human gene structure and functional characterization of its core promoter. Mol Cell Biol 2008, 28(21):6609-6619.

56. Triboulet R, Mari B, Lin YL, Chable-Bessia C, Bennasser $Y$, Lebrigand $K$, Cardinaud B, Maurin T, Barbry P, Baillat V, et al: Suppression of microRNAsilencing pathway by HIV-1 during virus replication. Science (New York, NY) 2007, 315(5818):1579-1582.

57. Chasseigneaux S, Pastore M, Britton-Davidian J, Manie E, Stern MH, Callebert J, Catalan J, Casanova D, Belondrade M, Provansal M, et al: Genetic heterogeneity versus molecular analysis of prion susceptibility in neuroblasma N2a sublines. Arch Virol 2008, 153(9):1693-1702.
58. Burns M, Duff K: Cholesterol in Alzheimer's disease and tauopathy. Ann N Y Acad Sci 2002, 977:367-375.

59. Valenza M, Rigamonti D, Goffredo D, Zuccato C, Fenu S, Jamot L, Strand A, Tarditi A, Woodman B, Racchi M, et al: Dysfunction of the cholesterol biosynthetic pathway in Huntington's disease. J Neurosci 2005, 25(43):9932-9939.

60. Valenza M, Cattaneo E: Cholesterol dysfunction in neurodegenerative diseases: is Huntington's disease in the list? Prog Neurobiol 2006 80(4):165-176.

61. Ohm TG, Treiber-Held S, Distl R, Glockner F, Schonheit B, Tamanai M, Meske $\mathrm{V}$ : Cholesterol and tau protein-findings in Alzheimer's and Niemann Pick C's disease. Pharmacopsychiatry 2003, 36(Suppl 2):S120-S126.

doi:10.1186/1471-2164-13-486

Cite this article as: Montag et al:: A genome-wide survey for prionregulated miRNAs associated with cholesterol homeostasis. BMC Genomics 2012 13:486.

\section{Submit your next manuscript to BioMed Central and take full advantage of:}

- Convenient online submission

- Thorough peer review

- No space constraints or color figure charges

- Immediate publication on acceptance

- Inclusion in PubMed, CAS, Scopus and Google Scholar

- Research which is freely available for redistribution

Submit your manuscript at www.biomedcentral.com/submit 